\title{
The Morphosyntax of the Demonstrative System in Classical Arabic: A Distributed Morphology Account
}

https://doi.org/10.33806/ijaes2000.20.1.2

\author{
Muteb Alqarni \\ King Khalid University, Kingdom of Saudi Arabia
}

\begin{abstract}
The current article explores the morphosyntax of the demonstrative system in Classical Arabic (CA) within the framework of Distributed Morphology (Halle and Marantz 1993, 1994; Halle 1997; and Embick and Noyer 2005). The paper decomposes the demonstratives into bimorphemic forms. The first morphemes represent the deictic information and capture the three types of demonstratives in CA: proximal, medial and distal. The second morphemes bear number, gender and case features which are presumably copied from the modified noun phrase. In this article, I show that the under specification of the demonstrative vocabulary items can account for all the patterns under study. However, in certain cases, context-sensitive features are required to reconcile the competition between equally competitive candidates. To account for unpredictable gaps in the paradigm, where the distal dual demonstratives are missing, I formulate an impoverishment rule as proposed by Zwicky(1985), Stump (1993) and Noyer (1998) who equip such rules with feature-changing capabilities.
\end{abstract}

Keywords: Classical Arabic, demonstratives, distributed morphology

\section{Introduction}

Demonstratives, such as this, that, these and those in English, are traditionally known as pointing words that refer to the distance of an object from the interlocutors ${ }^{1}$. Diessel (1990) offers three criteria to separate demonstratives from other grammatical classes: (i) they are deictic (i.e. pointing) expressions, (ii) they organize the flow of the speech by attracting the listener's attention to the object referred to, and (iii) they encode the interpretation of spatial distance. In the same line of argumentation, Dixon (2003:85) emphasizes that "the major parameters of reference for demonstratives are: spatial -- sometimes extended to temporal-location, height and stance, and visibility", concluding that the unique property of demonstratives is spatial reference. Such a characteristic has gained a universal status in the literature as in the works of Cowell (1964) for Syrian Arabic; Greenbaum and Quirk (1990) for English; Thackston (2000) for Classical Arabic; and Enfield (2003) for Lao among many others.

In Arabic traditional grammar books, demonstratives are termed as Psma:?ul-Pifa:rati'nouns of pointing' (Fischer 2002; Ryding 2005; Sawaie 2014 inter alia). They are characterized as nouns because they behave like nominal modifiers occuring before or after the Determiner Phrase (DP). Consider the 
following examples where the demonstrative $h a$ :ða'this' occurs pre-nominally as in (1a) or postnominally as in (1b).
1. a.
qara?tu
ha:ða 1-kita:b-a
read.1.SG.PERF this the-book-ACC
'I read this book'

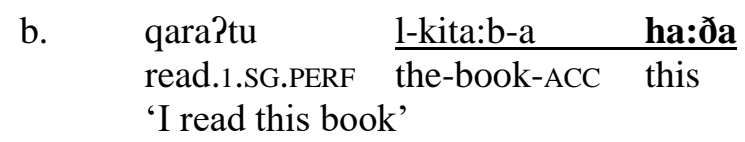

In this study, I will analyze all the possible demonstratives in CA, i.e. the old Arabic version that has been used since the 7th century AD until the 9th century AD. I derived the CA demonstratives from Hassan(1987:321-333, vol. 1) and presented them in Paradigm (1). Some of these CA demonstratives ceased to exist in Modern Standard Arabic (MSA).

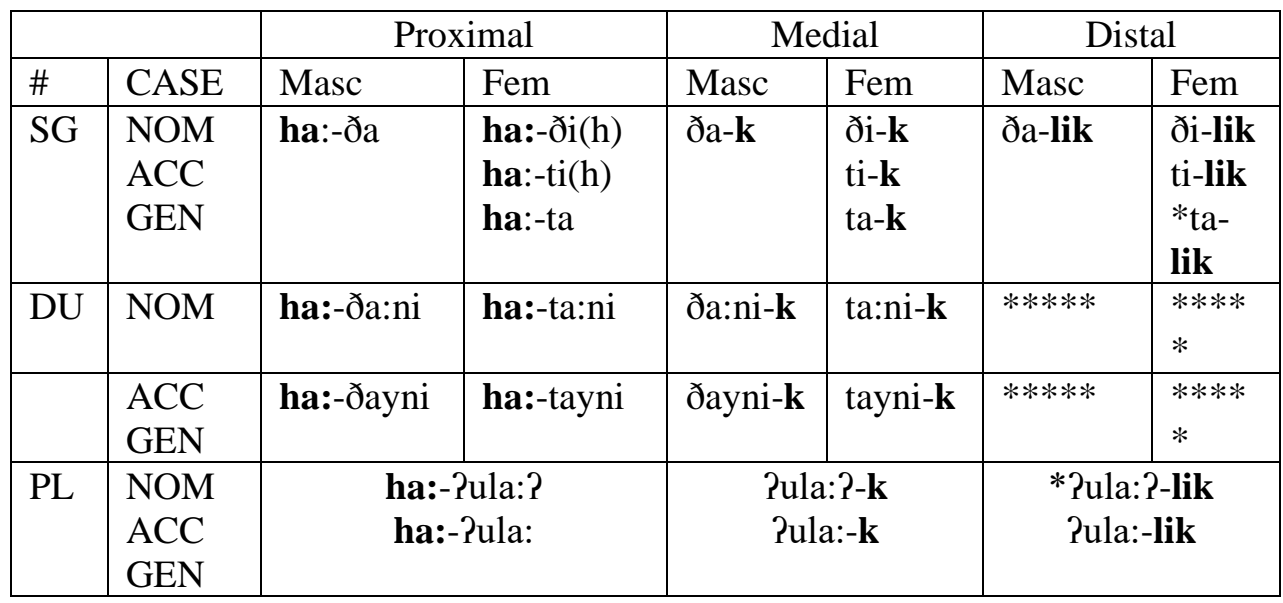

Paradigm 1: Demonstrative Paradigm in Classical Arabic

In Paradigm (1), Arabic demonstratives have a three-way distinction in terms of spatial deixis: (i) proximal, (ii) medial and (iii) distal. These distinctions are represented as affixes. The proximal morpheme refers to close objects and appears as the prefix ha:-. The distal morpheme surfaces as the suffix -lik referring to distant objects. As for the medial morpheme, it refers to objects which are neither close nor distant, and it is manifested in the suffix $-k$.

Arabic demonstratives are also marked for gender and number. As demonstrated in Paradigm (1), the singular masculine demonstrative is $\partial a$ whereas the feminine counterpart has three allomorphs: $\partial i(h), t i(h)$ and $t a$. As for the plural demonstrative ?ula:(?), it is gender-neutral. The first two feminine demonstratives $\partial i(h)$ and $t i(h)$ end with the glottal fricative $/ \mathrm{h} /$ whereas the plural morpheme Pula:(?) ends in the glottal stop / $/$. These glottals are dropped in the medial or distal contexts. Yet, the glottal stop $/ 2 /$ is retained with the medial morpheme $-k$. 
It is worth noting that the singular and plural morphemes show no case distinctions, i.e. they are invariable in all syntactic positions. In contrast, the dual number inflects for gender and case. In subject positions where nominative is assigned, the dual masculine morpheme is $\partial a$ :niwhereas the feminine counterpart is ta:ni. In object or prepositional object positions where accusative and genitive are licensed respectively, the dual masculine morpheme becomes Jayniwhile the feminine counterpart is tayni.

Although Arabic noun phrases and their nominal modifiers have been the focus of many studies (e.g. AlBarrag 2014and AlQahtani 2016 for nouns; Albuhayri 2013 and Alqarni 2018 for pronouns; Alghamdi 2015 for indefinite articles; Alqassas 2013 for the definite article; Ahmed 2015 for adjectives and Alqarni 2015 for numerals), demonstratives have not undergone any morphological analysis thus far. In this article, I will provide the first formal account to CA demonstratives, couching them within the Distributed Morphology (DM) framework (Halle and Marantz 1993 1994; Marantz 1997a,b; Halle 1997; Harley and Noyer 1999; Embick and Noyer 2005). I will show that DM can handle all the Arabic demonstrative patterns under study.

The remainder of the paper will be organized as follows. In the next section, I will present the DM framework. In section (3), I will discuss the vocabulary items representing the morphemes in Paradigm (1). I will provide an analysis to the whole CA demonstrative system insection (4). Closing remarks will be given in section (5).

\section{Distributed morphology framework}

Distributed Morphology is a morphological framework originating from the Minimalist Program (Chomsky 1995, 2000, 2001, 2004 et seq, henceforth MP). Unlike MP that posits the lexicon as a generative engine of complex words, Halle and Marantz $(1993,1994)$ present DM as a non-lexicalist approach putting more focus on the syntax-morphology interface (at PF).In DM, the machineries of lexicon as a creator of words is "dead, deceased, demised, [and] no more" (Marantz 1997a:2) since syntax is the only system that generates words, phrases and sentences.

Given that the lexicon in DM loses its generative task, it is distributed among three lists: List A, B and C.List A provides the syntactic computation with abstract information such as morphosyntactic and semantic features from Universal Grammar (UG). These features are common in all languages, such as [pl] for plural, [sg] for singular, [fem] for feminine etc. List A also provides the syntax with language-particular roots (Embick and Noyer, 2005, 2008).

At PF, the structure is fed with the appropriate phonological content from List B in an operation known as Vocabulary Insertion. List B contains phonological exponents, aka Vocabulary Items (VIs), associated with the features on the nodes. To illustrate, if the head D bears [+def], the VI/ðə/ will be inserted in $\mathrm{D}$ position and discharges the feature [+def] in an operation called Feature Discharge (Harley and Noyer 1999). As for the roots, the debate is still ongoing whether they enter the syntax as phonological units or in an abstract non-phonetic 
format, receiving their phonological support at PF (for a detailed discussion of this issue, see Marantz 1997b, Acquaviva 2008, De Belder 2011, Harley 2014).

Prior to feature discharge, Morphological Structure (MS) influences the structure and the feature content.At MS, the structure may undergo morphological operations where terminal nodes are raised, lowered, merged etc; thus, head-tohead movement is part of this stage. Also, at MS, totally new (non-semantic) features or nodes, called dissociated features/nodes, are added under certain conditions, especially for agreement/case purposes (Embick 1997, 1998).At this point, features may as well undergo operations such as impoverishment, fusion and fission. These three operations manipulate and modify the feature content or distribution.

As for List C, known as the Encyclopedia, it is the most under-researched component in the DM literature. Nevertheless, the same pattern of pairing between features and their equivalent VIs occurs at LF as well (for more details, see Harley and Noyer 1999).

To sum up, DM distributes the lexicon into three lists: List A, List B and List C. All these steps are schematized by Marantz (2000:204) in the following Ytree given in (2).

\section{Distributed Morphology Grammar Architecture}

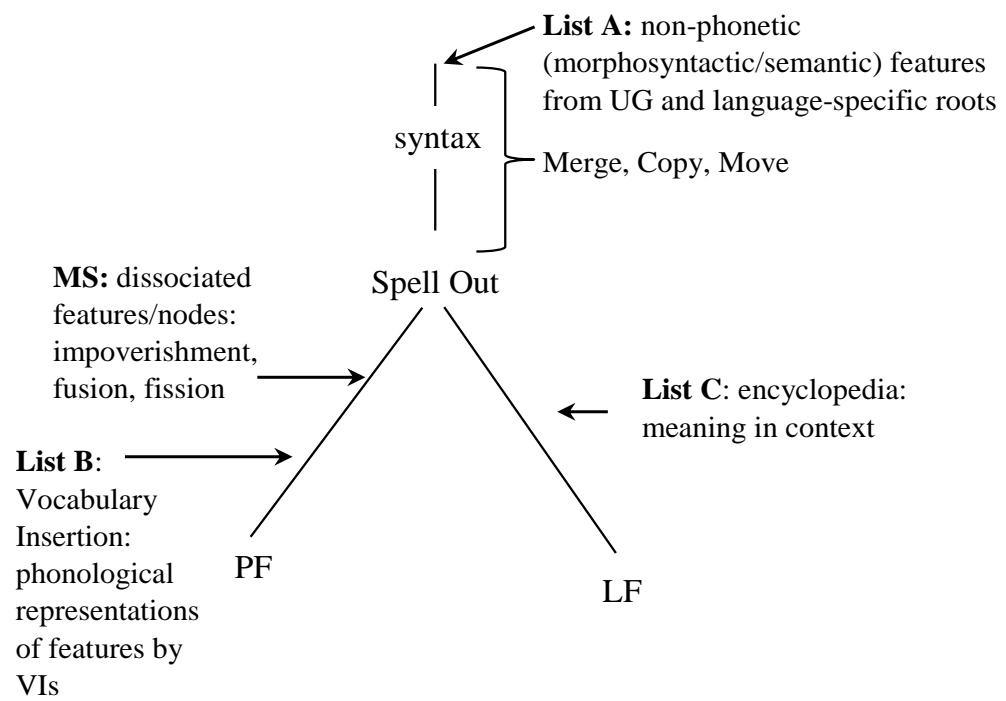

In the next section, I will develop a DM-based analysis to CA demonstratives in light of the principles and assumptions discussed above. 


\section{Vocabulary items of Arabic demonstrative system}

In this section, I will list the vocabulary items needed for the spell-out of CA demonstratives. This task requires the association of the demonstrative pieces with their relevant corresponding features.

As shown in Paradigm (1) above, demonstratives inflect for number, gender, case and spatial deixis (proximal, medial and distal). Starting with spatial deixis, CA demonstratives have a three-way distinction: proximal (ha:-), medial ($k$ ) and distal (-lik). To capture these distinctions, I propose the following two features ([proximal] and [distal]) as shown in Paradigm (2).

\begin{tabular}{lll}
\hline Object & Proximal & Distal \\
\hline Close & + & - \\
Distant & - & + \\
Close-Distant (Medial) & + & + \\
\hline
\end{tabular}

Paradigm 2: Features of Deictic Information Encoded in CA Demonstratives.

In short, morphemes that refer to close objects are associated with [+proximal -distal] whereas those referring to distant ones are represented with [+distal proximal]. As for the demonstratives for both close and distant objects, they are simultaneously specified with the two features: [+proximal +distal]. Under these assumptions, I propose that the VIs which express the deictic features in Arabic are underspecified as listed in (3).

3. VIs For Deictic Features

$$
\begin{array}{lll}
\text { /ha:/ } & \longleftrightarrow & \text { [+proximal] } \\
/ \mathrm{k} / & \longleftrightarrow & \text { [+proximal +distal] } \\
\text { /lik/ } & \longleftrightarrow & \text { [+distal] }
\end{array}
$$

For number, I will specify singular with $[+\mathrm{sg}]$ and plural with $[+\mathrm{pl}]$. In the same fashion of treating medial demonstratives above and following Harley and Ritter's (2002:18) feature geometry and their treatment of dual as "the simultaneous activation of Minimal [i.e, singular] and Group [i.e., plural]", I will associate dual with the coupled features [ $+\mathrm{sg}+\mathrm{pl}]$. Concerning gender in Arabic, it has a two-way distinction: masculine and feminine. Masculine is represented with [+masc] whereas feminine is associated with [+fem].

Regarding case, I will adopt Halle's (1997) and Embick and Noyer's (2005:17) decomposition of Latin case and extend it to Arabic. In their proposal, the case features are as demonstrated in Paradigm (3): nominative case is specified with [+sup -obl] while genitive is associated with [+obl -sup]. Accusative is the default option, i.e. [-sup -obl]. 


\begin{tabular}{llll}
\hline & Nominative & Accusative & Genitive \\
\hline Superior & + & - & - \\
Oblique & - & - & + \\
\hline
\end{tabular}

Paradigm 3: Arabic Case Features

After associating every morpheme with its relevant features, let us turn to the VIs needed to discharge the number and gender features in the CA demonstrative system. As obvious from Paradigm (1), the singular masculine demonstrative is /ða/ whereas the feminine counterpart has three allomorphs: $/ ð \mathrm{i}(\mathrm{h}) /, / \mathrm{ti}(\mathrm{h}) /$ and $/ \mathrm{ta} /$. Thus, the tentative proposal of these patterns will beaslisted in (4).

4. VIs For Singular Demonstratives

$$
\begin{array}{lll}
/ \text { aa/ } & \longleftrightarrow & {[+\mathrm{masc}+\mathrm{sg}]} \\
/ \mathrm{di}(\mathrm{h}) / & \longleftrightarrow & {[+\mathrm{fem}+\mathrm{sg}]} \\
/ \mathrm{ti}(\mathrm{h}) / & \longleftrightarrow & {[+\mathrm{fem}+\mathrm{sg}]} \\
/ \mathrm{ta} / & \longleftrightarrow & {[+\mathrm{fem}+\mathrm{sg}]}
\end{array}
$$

In (4), the VI /ða/ is associated with the features [+masc $+\mathrm{sg}$ ] whereas the other feminine allomorphs are all specified with $[+\mathrm{fem}+\mathrm{sg}]$. At first sight, the proposal in (4) is problematic because the final glottal fricative $/ \mathrm{h} /$ in Paradigm (1) is dropped in the medial and distal contexts, i.e. with $/ \mathrm{k} /$ and /lik/ respectively. Also, the list in (4) should rule out the VI/ta/ from inserting into the node of distal morpheme, because /*ta-lik/ is illicit in CA. To capture these facts, we should contextualize the different feminine allomorphs and limit their insertion chances. Thus, I propose that the VI list in (4) should be revised as given in (5).

5. VIs for Singular Demonstratives

$$
\begin{aligned}
& / \text { /a/ } \longleftrightarrow \quad[+ \text { masc }+ \text { sg }] \\
& / \text { ðih/ } \longleftrightarrow \quad[+ \text { fem }+ \text { sg }] \quad \text { \{+proximal -distal }\} \\
& / \text { tih } / \longleftrightarrow \quad[+ \text { fem }+\mathrm{sg}] \quad \text { \{tproximal -distal }\} \\
& / ð \mathrm{i} / \quad \longleftrightarrow \quad[+\mathrm{fem}+\mathrm{sg}] \\
& / \mathrm{ti} / \quad \longleftrightarrow \quad[+\mathrm{fem}+\mathrm{sg}] \\
& \text { /ta/ } \longleftrightarrow \longrightarrow \quad[+\mathrm{fem}+\mathrm{sg}] \quad\{+ \text { proximal }\}
\end{aligned}
$$

In (5), the allomorphs / $/ \mathrm{ih} /$ and /tih/ are now specified with contextual conditions. They only appear if the numeration contains \{+proximal -distal $\}$. In other words, if the demonstrative node is proximal bearing the features [+proximal -distal], the VIs which are given the priority to insert will be /ðih/ or /tih/.

If no contextual conditions are met, i.e. if the derivation involves medial or distal demonstratives, the elsewhere $\mathrm{VIs} / ð \mathrm{i} /$, /ti//, /ta/ will rather win the competition. Given that the structure of medial and distal demonstratives must 
involve at least [+distal] in their terminal nodes, this feature will preclude the insertion of /ðih/ and /tih/ which are contextually specified with \{-distal\}. Thus, we predict that the illict medial demonstratives /*ðih-k/ and /*tih-k/ or their distal counterparts /* ðih-lik/ and /*tih-lik/ are blocked and cannot be generated by any means.

Furthermore, the advantage of the proposal in (5) follows from the fact that it can capture another interesting pattern. It is observed from Paradigm (1) that the glottal fricative $/ \mathrm{h} /$ in proximal demonstratives is optional. These variations can be neatly captured under the proposal (5): if the most contextually specified VIs /ðih/ and /tih/ are not considered by the CA native speaker, the elsewhere VIs /ði/ and /ti/ still insert as a last resort.

One important issue to address is the mechanism that inhibits the VI/ta/ from inserting into the node of a distal demonstrative, i.e. [+distal -proximal]. Paradigm (1) shows that $/ *$ ta-lik/ is an unlawful demonstrative in CA. As shown in (5), the association of the $\mathrm{VI} / \mathrm{ta} /$ with a contextual feature $\{+$ proximal $\}$ will eliminate /ta/ from competition if distal demonstratives are at play. In brief, the VI $/ \mathrm{ta} /$ will only compete if the structure has [+proximal], and this feature exclusively appears during the derivation of proximal demonstratives, i.e. [+proximal -distal], plus medial demonstratives endowed with [+proximal +distal]. In either case, [+proximal] is available.

Notice that all the VIs in (5) are underspecified for case. That is, they are not associated with case features such as [+sup] for nominative, [+obl] for genitive or [-sup -obl] for accusative. The under specification of these VIs in case is advantageous given that it licenses all these demonstratives in all syntactic positions without constraints. The same situation appears in the plural demonstrative, /Pula:(?)/, which is not specified for case, neither is it marked for gender. Given that the final glottal stop /?/ in the plural morpheme / $\mathrm{Pula(?)/ \text {is }}$ optional, and it is banned with the distal suffix /lik/ in Paradigm (1), I propose that there are two plural allomorphs as in $(6)^{2}$.

6. VIs for Plural Demonstratives

$\begin{array}{lll}\text { Pula:? } & \leftarrow & {[+\mathrm{pl}]} \\ \text { Pula: } & \leftarrow & {[+\mathrm{pl}]}\end{array} \quad\{+$ proximal $\}$

In (6), I assume that /Pula:/ is the default VI, occurring with all demonstratives: proximal, medial and distal, see Paradigm (1). However, the VI /Pula:?/ is exclusive to the numeration that involves [+proximal] only. Given that the structure of distal demonstrative is enriched with the features [+distal proximal], the VI /Pula:?/, being context-sensitive to $\{+$ proximal $\}$, is blocked from insertion. The VI /?ula:?/ requires a configuration that involves at least [+proximal]. It will be thus restricted to the contexts of proximal and medial demonstratives endowed with [+proximal] plus other irrelevant features [+/distal].

In contrast to the VI lists in (5) and (6) where both the singular and plural morphemes have no case alternations, the dual number is specified for both 
gender and case. In nominative positions, for instance, the dual morpheme is /ða:ni/ for masculine and /ta:ni/ for feminine. In accusative and genitive positions, the dual morpheme inflects as /ðayni/ for masculine or /tayni/ for feminine. Thus, I propose the following VI list in (7) for dual demonstratives.

7. VIs for Dual Demonstratives

$$
\begin{aligned}
& \text { /ða:ni/ } \longleftrightarrow \quad[+\mathrm{pl}+\mathrm{sg}+\text { masc }+ \text { sup }] \\
& \text { /ta:ni/ } \longleftrightarrow \quad[+\mathrm{pl}+\mathrm{sg}+\mathrm{fem}+\text { sup }] \\
& \text { /ðayni/ } \longleftrightarrow \quad[+\mathrm{pl}+\mathrm{sg}+\text { mas }] \\
& \text { /tayni/ } \longleftrightarrow \quad[+\mathrm{pl}+\mathrm{sg}+\mathrm{fem}]
\end{aligned}
$$

In (7), only nominative variants /ða:ni/ and /ta:ni/ are associated with the nominative feature [+sup]. The variants /ðayni/ and /tayni/ are the elsewhere cases, being unmarked for case. This will enable the VIs /ðayni/ and /tayni/ to occur in all contexts other than the nominative (i.e. subject) position.

In this section, I constructed the lists in (5), (6) and (7) based on the demonstrative patterns of Paradigm (1), assuming that they are capable of deriving all the number/gender/case facts under study. Putting all these lists together, the whole VI list for CA demonstratives will be as follows.

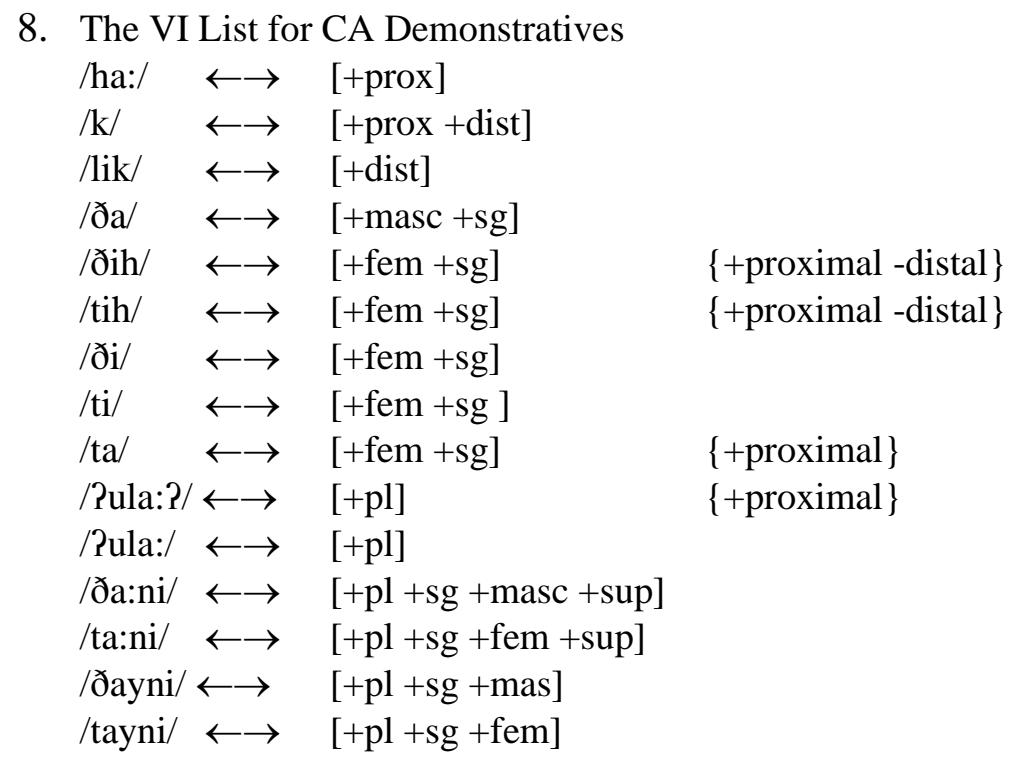

In the following section, I will show how the VI list in (8) can generate all the wanted forms and under generate the undesirable ones.

\section{A DM-based derivation of CA demonstratives}

In this section, I will illustrate the derivation of the demonstratives in CA. Section (4.1) will address the structural location of demonstratives, and the mechanisms 
needed to distribute and copy the features from the DP to the demonstrative head before Vocabulary Insertion stage. In section (4.2), I will show how the CA demonstratives are morphologically expressed, accounting for the illicit forms blocked from realization. I will evaluate an alternative proposal in the final section (4.3) showing its inferiority to the proposal given in section (4.2).

4.1. Structural position of CA demonstratives

Recall that CA demonstratives optionally precede or follow definite noun phrases as illustrated in the example (1) reproduced in (9).

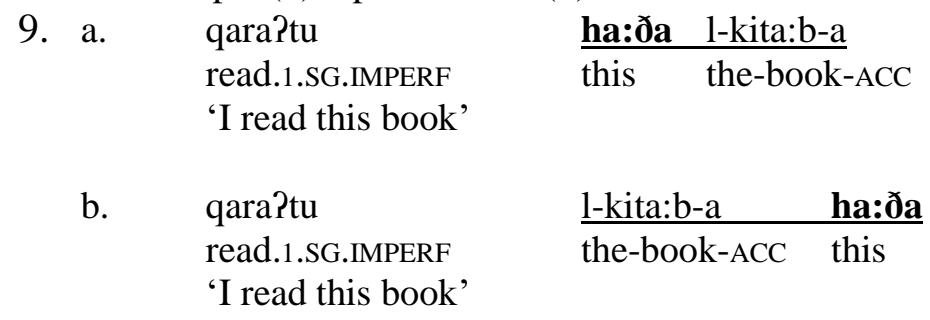

In light of this linear ordering, I propose that CA demonstratives head their own projection as a Demonstrative Phrase (DemP). I further assume that this DemP is a functional layer dominating the whole DP as shown in the diagram (10a), and such a position is apt for the pre-nominal demonstrative in (9a). As forthe post-nominal demonstrative in (9b), it can be still derived via DPmovement from its original position to spec,DemP as in (10b) (for a detailed discussion of the demonstrative syntax in the spine of DP, see Mohammad 1988; Fassi-Fehri 1999; Shlonsky 2004 among others).

10. a. Prenominal Demonstratives

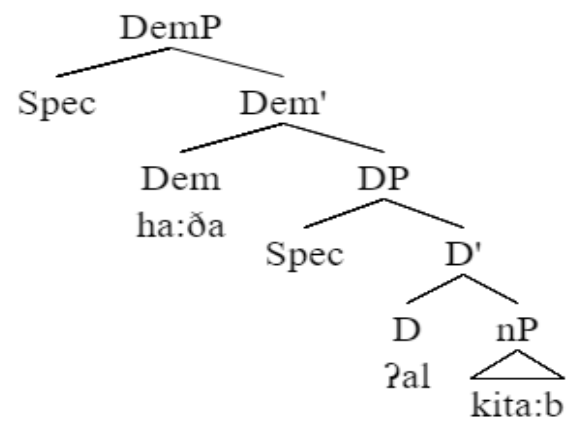

b. Postnominal Demonstratives

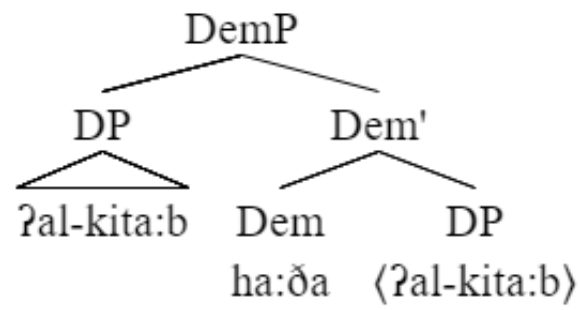


Concerning the feature distribution, I propose that the head Dem carries only the deictic features, i.e. [+/- proximal] and [+/-distal]. As for number, gender and case features, I assume that CA demonstratives copy them from their modified noun phrase. This assumption is compatible with the fact that demonstratives fully agree with their modified nouns in number, gender and case as shown in the data below.

\begin{tabular}{|c|c|c|c|}
\hline 11. a. & $\begin{array}{l}\text { ha:ða:ni } \\
\text { DEM.M.DU.NOM } \\
\text { 'These two boo }\end{array}$ & $\begin{array}{l}\text { l-kita:b-a:ni } \\
\text { the-book.M-DU.NOM } \\
\text { k were read' }\end{array}$ & $\begin{array}{l}\text { quri?a: } \\
\text { read.PASS.M.DU }\end{array}$ \\
\hline b. & $\begin{array}{l}\text { ha:ta:ni } \\
\text { DEM.F.DU.NOM } \\
\text { 'These two ma }\end{array}$ & $\begin{array}{l}\text { 1-madzall-at-a:ni } \\
\text { the-magazine-F-DU.NOM } \\
\text { gazines were read' }\end{array}$ & $\begin{array}{l}\text { quriPata: } \\
\text { I read.PASS.F.DU }\end{array}$ \\
\hline 12. a. & $\begin{array}{l}\text { qaraPtu } \\
\text { read.1.SG.PERF } \\
\text { 'I read these tw }\end{array}$ & $\begin{array}{ll}\text { ha:ðayni } & \text { l-kita:b } \\
\text { DEM.M.DU.ACC } & \text { the-boc } \\
\text { o books' } & \end{array}$ & $\begin{array}{l}\text { o-ayni } \\
\text { ok.M-DU.ACC }\end{array}$ \\
\hline b. & $\begin{array}{l}\text { qara?tu } \\
\text { read.1.SG.PERF } \\
\text { 'I read these tw }\end{array}$ & $\begin{array}{ll}\text { ha:tayni } & \text { 1-madz } \\
\text { DEM.F.DU.ACC } & \text { the-ma } \\
\text { o magazines' } & \end{array}$ & $\frac{\text { al-at-ayni }}{\text { gazine-F-DU.ACC }}$ \\
\hline
\end{tabular}

In (11a), the phrase /alkita:ba:ni/ 'two books' is a masculine dual NP appearing in a subject position, i.e. taking the nominative case. The demonstrative /ha:ða:ni/ agrees with this NP and displays dual, masculine and nominative properties as well. The same applies to the feminine dual nominative NP, i.e. /almadzalata:ni/, with which the demonstrative /ha:ta:ni/ fully agrees, see (11b). If these noun phrases appear as an object of the verb as in (12a,b), i.e. taking the accusative case, the demonstratives /ha:ðayni/ and /ha:tayni/ also decline for case, number and gender. The full agreement between demonstratives and NP is still invoked post-nominally as shown in (13) and (14).

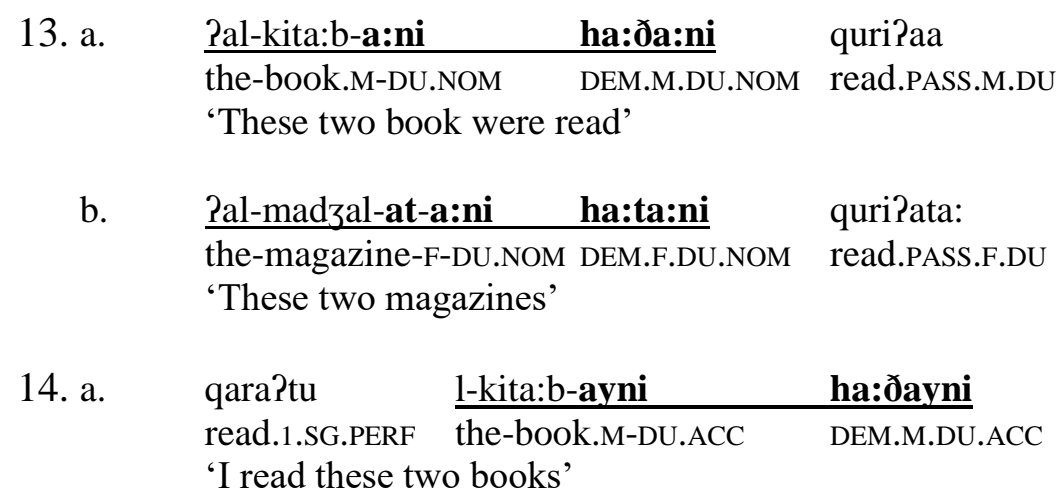




\section{b. qara?tu 1-madzal-at-ayni ha:tayni \\ read.1.SG.PERF the-magazine-F-DU.ACC DEM.F.DU.ACC \\ 'I read these two magazines'}

In light of these observations, I will argue that the nominal features related to number and gender appear within the DP hierarchy in Gender Phrase (GenP) for gender (cf. Picallo 1991) and Number Phrase (NumP) for number (cf. Ritter 1991). As for case, it is hypothesized that it is a non-semantic feature being assigned at PF from an external functional head such as $\mathrm{T}$ for nominative, $\mathrm{v}$ for accusative or P for genitive (Marantz 1991; Bobaljik 2008).

Thus, the dual feminine nominative NP in (11b) is schematized in the following simplified tree in (15).

15.

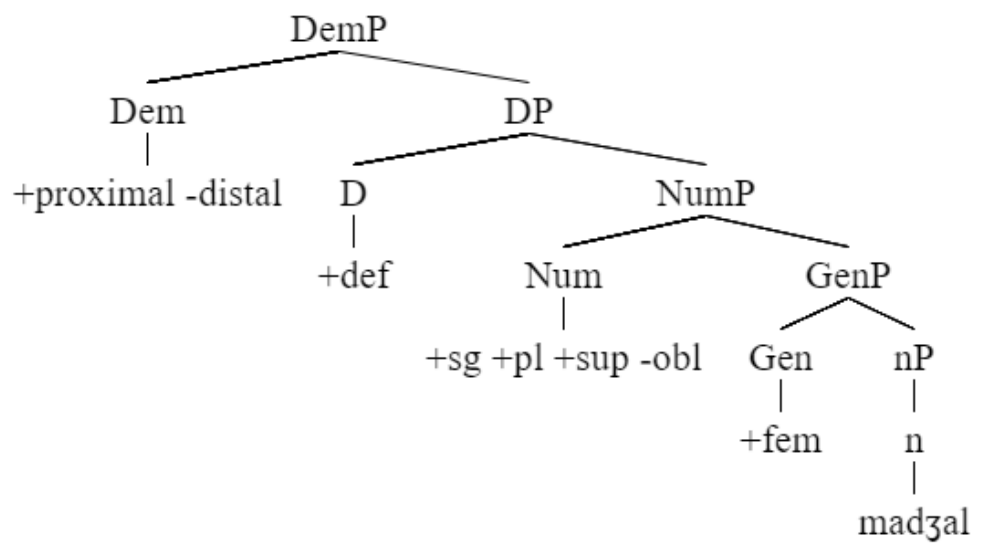

During the derivation of the demonstrative phrase /ha:ta:nil-madzal-at-a:ni/ 'these two magazines' in (11b), the structure will be endowed with the features as shown in (15). The deictic features [+proximal -distal] that represent proximal demonstratives will appear on the head node Dem. The gender feature [+fem] will be encoded in Gen, whereas the dual features $[+\mathrm{sg}+\mathrm{pl}]$ will occur under Num. As for the nominative case features [+sup -obl], they are assigned from $\mathrm{T}$ and are theoretically added on the head D post-syntactically according to Marantz (1991) and McFadden (2004) as in (16a) or in certain cases passed to Num according to Embick and Noyer (2005) as in (16b).

$$
\begin{array}{ll}
\text { 16. } & \text { a. } \\
\text { b. } & \text { Num } \rightarrow \text { D }
\end{array}
$$

I presume that the case features in Arabic are passed to Num as diagrammed in (17). Thus, these phi features will be realized at spell-out during the VI insertion stage as follows. 
17.

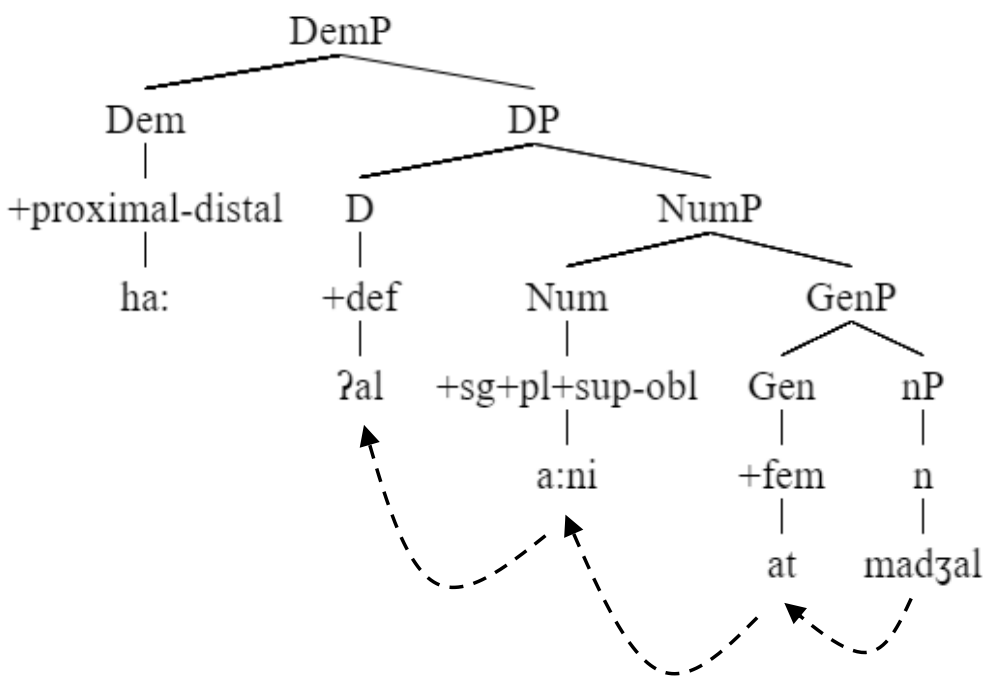

To linearize these phonological strings, the nominal root /madzal/ will raise in successive head-to-head movementsup to the head D. The head noun /madzal/ first lands on the head Gen and attaches to the morpheme /at/, yielding /madzalat/. The n-Gen combination /madzal-at/ proceeds and left-adjoins to the head Num collecting the morpheme /a:ni/, yielding /madzal-at-a:ni/, which raises in a final step to collect the definite article / $\mathrm{Ral} /$ and yeild the final output / $\mathrm{Ral}$-madzal-ata:ni $/ 3$.In line with Mirror Principle (Baker 1985) and its relaxed version (Harley 2010), these transformations stipulate that the order of the morphemes with respect tothe noun will be the mirror image of their hierarchical order.

According to the derivation in (17), the final output will be /ha:-Pal-madzalat-a:ni/ 'these two magazines' which is a possible form only in the Arabic dialects, where the demonstratives do not need to agree in gender, number and case with the modified NP. However, this output is outlawed in CAdue to a requirement that demonstratives must induce a full agreement with their modified nouns.

For demonstratives to be spelled out in CA, they need to agree with the internal features of the DP. Here, I posit that the agreement between demonstratives and DP is accomplished via a copy operationaftera dissociated node for Agreement (AGR) is added at PF to the head Demaccording tothe rule (18) (see Embick 1997, 1998; Embick and Noyer 2005:14).

18. $\emptyset \rightarrow$ AGR $\quad\{$ Dem $\}$ at PF 
Rule (18) requires that an AGR node be added to the head Dem. This newly added AGR will copy the phi features from the DP in an operation known asFeature Copying.

19. Feature Copying: A feature is present on a node in the narrow syntax is copied onto another node at PF (Embick and Noyer2005:16).

Therefore, I assume that, after the introduction of the AGR node and the application of Feature Copying, the structure in (17) will be as shown in (20).

20.

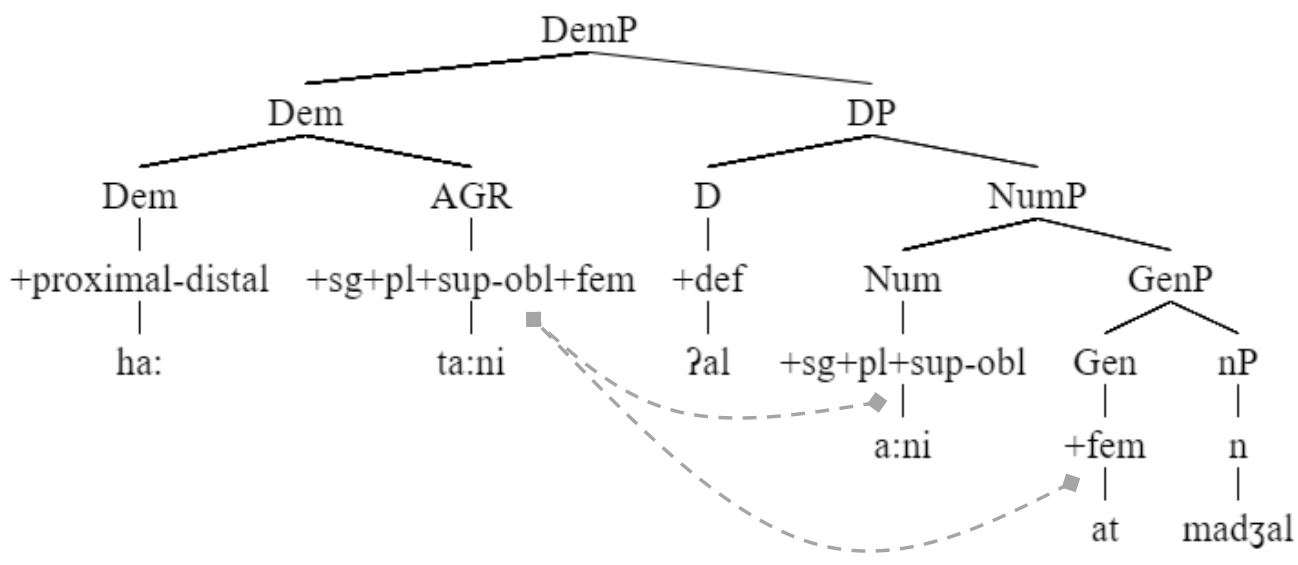

Note that the AGR node assembles all the number/gender/case features from the DP. The copy operation yields the correct demonstrative phrase /ha:ta:ni?almadzalata:ni/ 'these two magazines'. One might inquire why the [+def] is not copied altogether with the other phi features. I will first assume that [+def] is not copied by demonstratives since they are definite and referential elements from a semantic perspective (Dixon, 2003). Thus, it is superfluous for demonstratives to copy an additional definiteness feature to their domain. To make the scene clean, I will follow this hypothesis for the moment, but I will discuss the consequences of [+def] copying in section (4.3), showing that it will not cause any derivational problems either.

\subsection{Derivation of CA demonstratives}

In this section, I will discuss the competition of VIs in discharging the features on the demonstrative terminal nodes. Let us start with the most straightforward case: the proximal singular masculine demonstrative /ha:ða/ as shown in (21). 
21. The proximal masculine singular demonstrative /ha:ða/

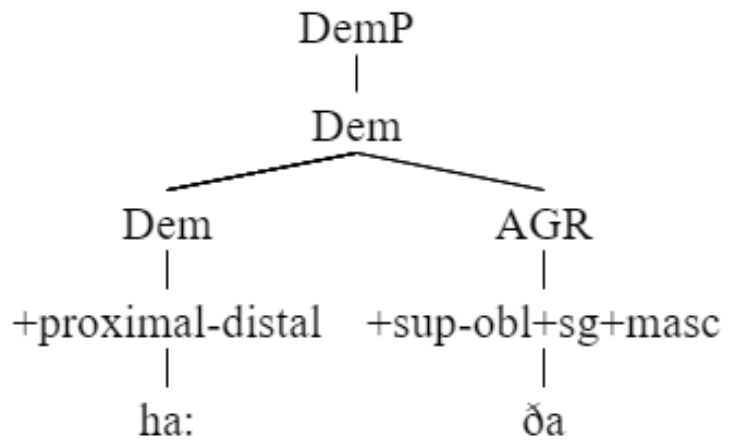

As shown in (21), in a hypothetical subject position, the structure of the demonstrative /ha:ða/ will be endowed with the deictic features [+proximal distal] on the head Dem, and the copied number and gender features [+sg +masc] and the nominative case features [+sup -obl] on the head AGR. At spell-out, the VIs in (22) will compete to discharge the features on every terminal node.

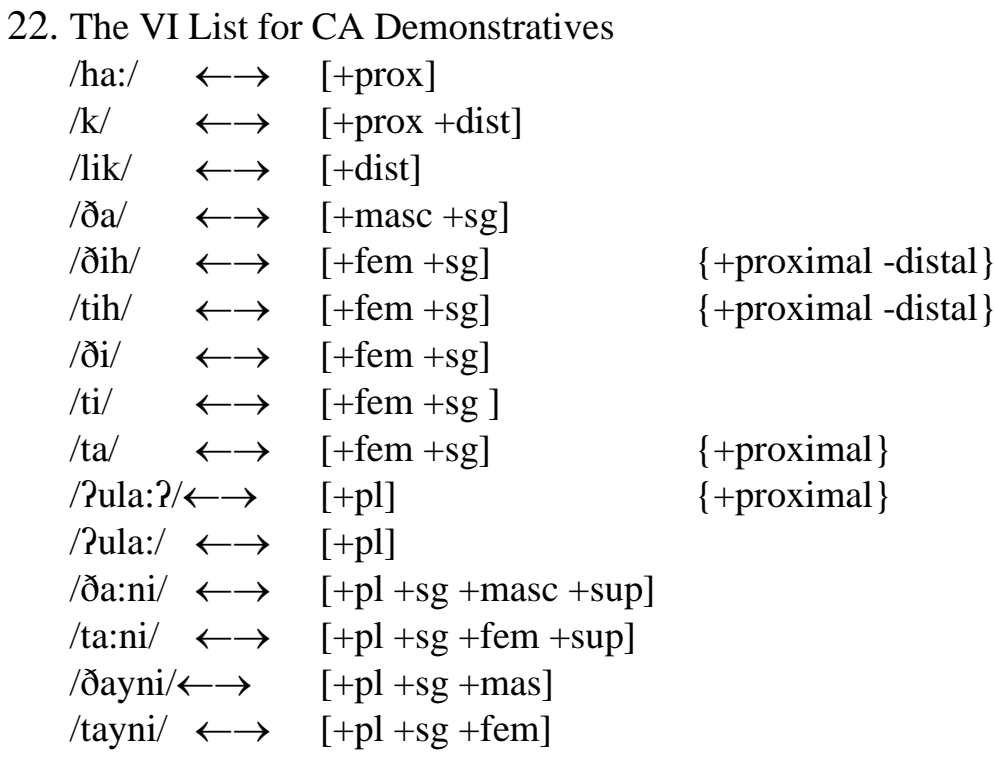

The VI /ha:/ will be selected for Demas it is the only exponent correlating with the feature [+proximal]. The VI / $/ \mathrm{k} /$ cannot insert into Dem for being associated with [+proximal +distal] and the node has a conflicting feature, namely [-distal]. The same applies to the unwanted VI /lik/ which is eliminated from the 
competition due to its associative feature [+distal] (not present in Dem). As for the other node, the best entry to slot into AGR bearing [+sup -obl +sg +masc] is the VI /ða/ associated with the maximal subset [+sg +masc]. As a final step, the merged two nodes in (21) will be pronounced as the desirable demonstrative /ha:ða/.

Let us now turn to the derivation of both the medial and distal forms of the same singular masculine demonstrative, i.e. /ðak/ and /ðalik/ respectively. Their derivations will be as drawn in (23a,b) respectively.

23. a. ðak

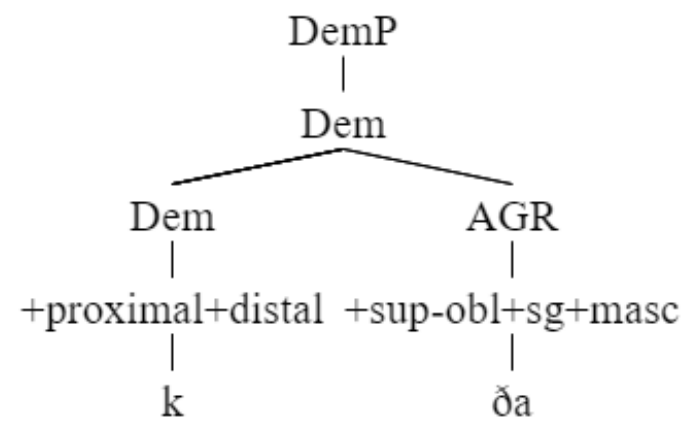

b. ðalik

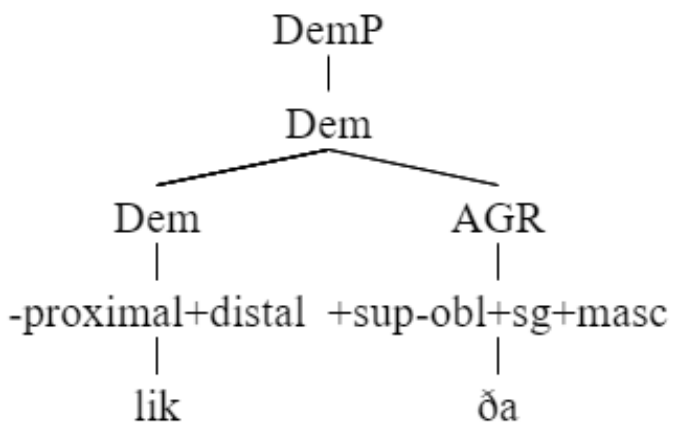

As noted earlier, the VI /ða/is the ideal candidate for realizing the features on the AGR node. However, Dem head will be differently represented. The features on Demarephonologically expressed as the VI / $/$ / (associated with [+proximal +distal]) as in (23a) or as /lik/ (specified with [+distal]) as in (23b). A problem in the derivations in (23) follows from the improper ordering ofthe VIs $/ \mathrm{k} /$ and /lik/appearing as prefixes although they should be adjoined onto Dem as suffixes. The required demonstrative forms are /ða-k/ and /ða-lik/ but the trees in (23) undesirably generate ungrammatical forms such as /*k-ða/ and /*lik-ða/. 
There are two solutions to the problem at hand. First, we know that the dissociated nodes such as AGR are adjuncts by nature. Given that adjuncts are inherently bidirectional (Cinque 1999; Dalrymple 2001; Ernst 2002), we can simply assume that AGR nodes can be adjoined either to the right or the left of the head Dem.Under this account, AGR node should be added to the left of Dem only in medial and distal contexts. We can therefore formulate a rule as in (24) that adjoins AGR to the left of the Dem in the environment of [+distal], an active feature in the domain of both medial and distal demonstratives.

\section{Dem $\rightarrow$ AGR DEM $\quad$ \{when Dem includes +distal $\}$}

In accordance with rule (24), i.e. when [+distal] is available on the head Dem, AGR is simply adjoined to the left of Dem as shown in (25).

25. a. ðak

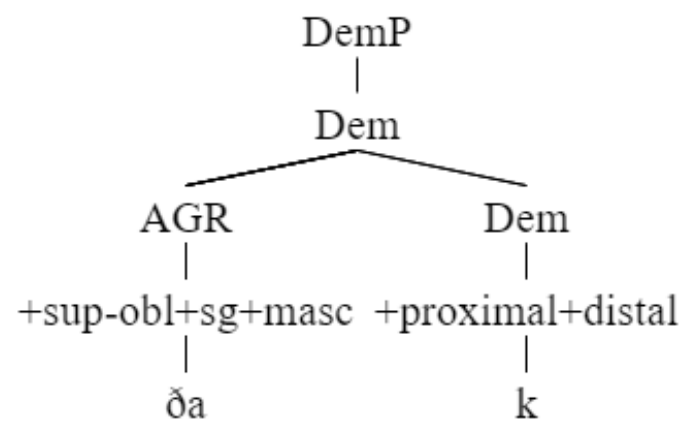

b. ðalik

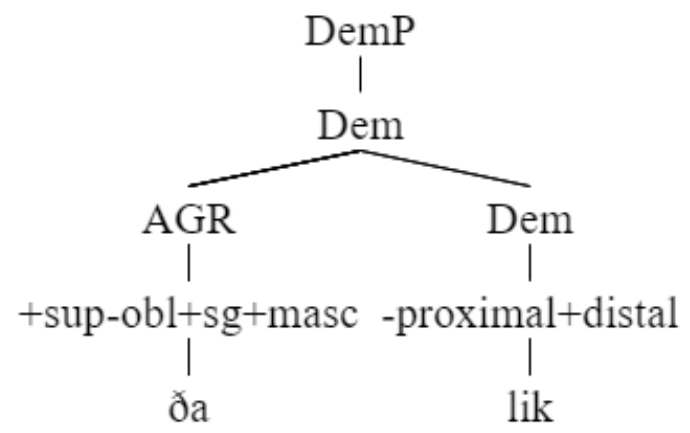

To obtain the same results in (25) under an alternative account, we can propose that the old structure in (23) is originally correct. However, there is a Local Dislocation Rule that occurs after the Vocabulary Insertion stage. This rule is employed in DM to linearize affixes (Embick and Noyer 2005:24). Therefore, we can postulate the Dislocation Rule in (26) to switch the illicit affixal order. 


\section{Dem AGR $\rightarrow$ AGR DEM $\quad\{$ when Dem has [+distal]}

After the application of rule (26), the structures will be identical to those in (25). In brief, both proposals are acceptable. The first proposal assumes that the ordering occurs before the Vocabulary Insertion, where AGR is automatically base-generated to the left of the head Dem in the context of [+distal], whereas the other proposal delays the affixal ordering after the VI insertion and triggers a Local Dislocation Rule.

Let us now move to the derivation of the singular feminine demonstratives. These demonstratives behave like the singular masculine ones. However, for the multiple feminine allomorphs in (27), the picture is rather complex.

27. VIs for Singular Feminine Demonstratives

$$
\begin{aligned}
& / \text { ðih/ } \longleftrightarrow \quad[+\mathrm{fem}+\mathrm{sg}] \quad \text { \{tproximal -distal }\} \\
& / \text { tih/ } \longleftrightarrow \quad[+ \text { fem }+ \text { sg }] \quad \text { \{tproximal -distal }\} \\
& / ð \mathrm{i} / \quad \longleftrightarrow \quad[+\mathrm{fem}+\mathrm{sg}] \\
& / \mathrm{ti} / \quad \longleftrightarrow \quad[+\mathrm{fem}+\mathrm{sg}] \\
& / \mathrm{ta} / \quad \longleftrightarrow \quad[+\mathrm{fem}+\mathrm{sg}] \quad\{+ \text { proximal }\}
\end{aligned}
$$

In (27), the VIs /ði/ and /ti/are less specified; therefore, they are the default items. However, the VI /ðih/ and /tih/ are only realized in proximal demonstratives, i.e. if the numeration involves [+proximal -distal]. The pieces /ðih/ and /tih/ cannot be cliticized onto the medial suffix /-k/(e.g. /*ðih-k/) or onto the distal one/-lik/ (e.g. /*ðih-lik/). Consider the derivation of the proximal singular feminine demonstratives below.

28. a. ha:-ðih/tih

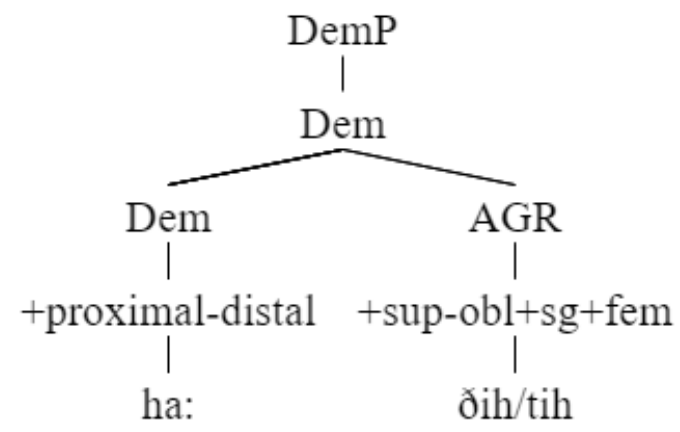


b. ha:-ði/ti/ta

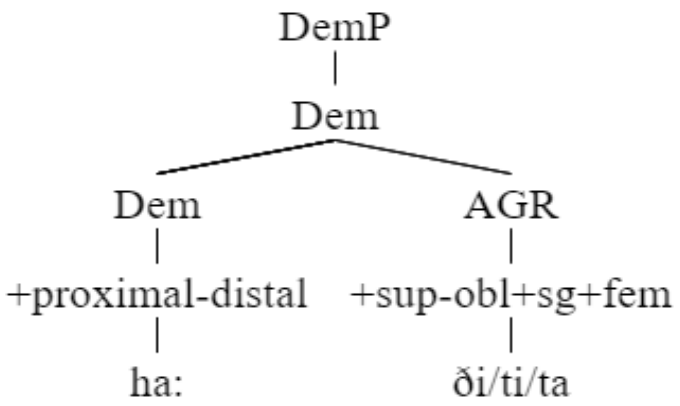

In $(28 \mathrm{a}, \mathrm{b})$, both structures start with the same features, but the AGR node can be supplied by either the most specified VI/ðih/and /tih/as in (28a) or the less specified /ði/, /ti/ and/ta/ as in (28b). Since all the candidates in (27) are equally strong, optionality is predictable. Yet, because the domain consists of [+proximal -distal] in (28a), the allomorphs /ðih/and /tih/ are more commonly used by CA speakers by virtue of the restrictions of these items to this occurrence, i.e. they are context-sensitive to the features $\{+$ proximal -distal $\}$. As in (28b), AGR can be alternatively supplied with the default VIs/ði/, /ti/and/ta/simply because these VIs are underspecified and can discharge the features $[+\mathrm{fem}+\mathrm{sg}]$ everywhere without conditions. Thus, the grammar of a native CA speaker will decide which variant is used, and this is a desirable conclusion from DM in handling the variations under question. Although the $\mathrm{VI} / \mathrm{ta} / \mathrm{is}$ specified with the feature $\{+$ proximal $\}$, this contextual feature does not tamper with the whole derivation due to the availability of [+proximal] in the configuration (28b); thus, the $\mathrm{VI} / \mathrm{ta} /$ is also licensed as a legitimate candidate.

However, the optionality discussed above for proximal demonstratives is not warranted in the case of medial and distal demonstratives that disallow the VI/ðih/ and /tih/from being attached with/-k/ or /-lik/ respectively. Consider the following derivations.

29. a.ði-k/ti-k/ta-k

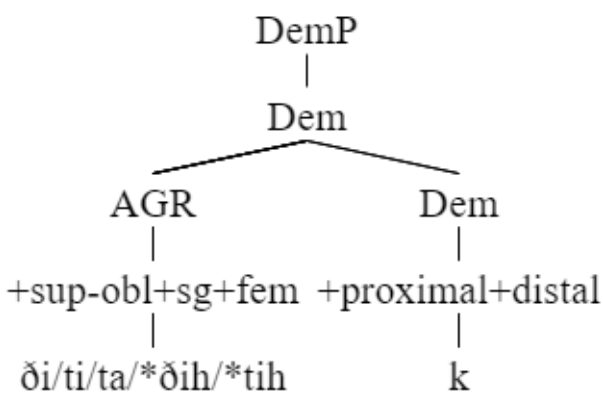


b. ti-lik/ði-lik

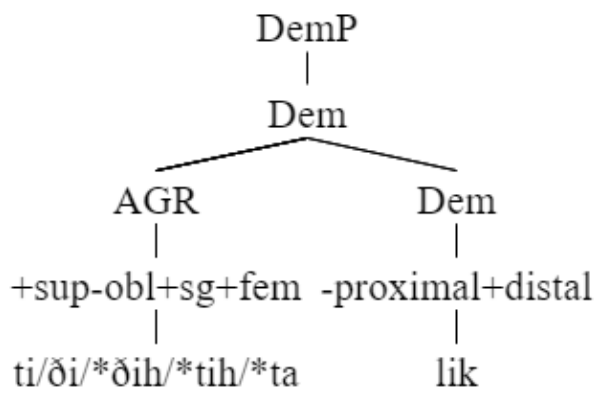

Note that the situation is different for singular feminine demonstratives when the structure involves features such as [+proximal +distal] for medial as in (29a) or [-proximal +distal] for distal as in (29b). In (29a), Dem is filled with [+proximal +distal], an environment which immediately eliminates the VI /ðih/and /tih/ from competition for their contextual conflicting features $\{+$ proximal -distal $\}$ in (27). The absence of [-distal] in (29a) precludes the VI /ðih/and /tih/ from insertion. Thus, the best exponents are the default VI /ði/and $/ \mathrm{ti} /$ and the $\mathrm{VI} / \mathrm{ta} /$ (specified with $\{+$ proximal $\}$ ).

As for structure (29b), it bears the features [-proximal +distal], which similarly exclude all the VIs /ðih/ and/tih/ plus the VI/ta/from competition for their context-dependent feature not present in the computation, viz. \{+proximal . The only candidates to insert in AGR in (29b)will be thus the elsewhere cases/ði/ and /ti/. As a conclusion, it is obvious that the VI list in (27) with the contextual features is on the right track in generating all the possible singular/feminine demonstratives and banning illicit forms.

In all the structures above, although the nominative features [+sup -obl] are available, they are not realized. If these features are replaced with [-sup +obl] for genitive or [-sup -obl] for accusative, the above derivations will not differ as the singular VIs are underspecified for case.

Let us now see the derivation of the dual demonstratives which inflect for case. Only nominative dual VIs are associated with case features as shown in the VI list (30).

30. VI list for Dual Demonstratives

$$
\begin{array}{ll}
\text { /ða:ni/ } \longleftrightarrow \longrightarrow & {[+\mathrm{pl}+\mathrm{sg}+\text { masc }+ \text { sup }]} \\
\text { /ta:ni/ } & {[+\mathrm{pl}+\mathrm{sg}+\text { fem }+ \text { sup }]} \\
\text { /ðayni/ } \longleftrightarrow & {[+\mathrm{pl}+\mathrm{sg}+\text { mas }]} \\
\text { /tayni/ } \longleftrightarrow \longrightarrow & {[+\mathrm{pl}+\mathrm{sg}+\text { fem }]}
\end{array}
$$


Deriving a representative for each form, the structure for proximal masculine dual nominative/genitive demonstratives will be as follows.

31. a. ha:-ða:ni

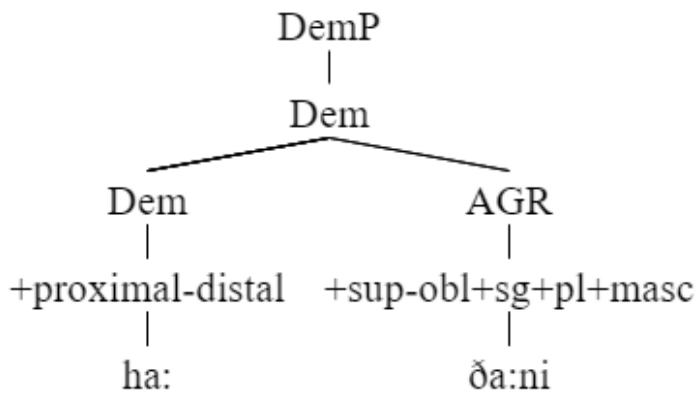

b. ha:-ðayni

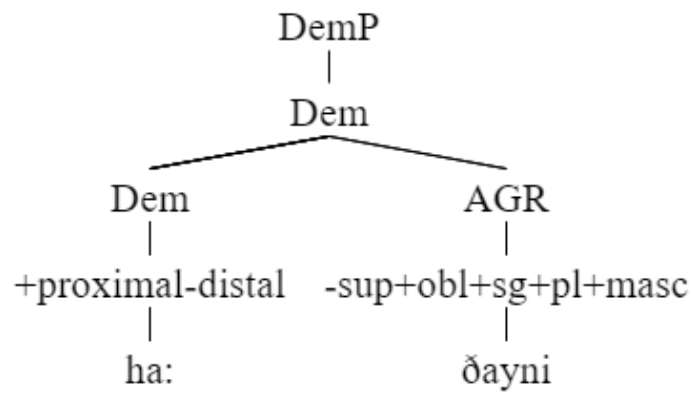

It is apparent that the AGR node in $(31 \mathrm{a}, \mathrm{b})$ bears the dual features [+sg $+\mathrm{pl}]$ and the masculine feature [+masc]. It also carriesthe nominative features [+sup obl] in (31a) or the genitive features [-sup +obl] in (31b). Under these hypothetical circumstances, no VIs in (22) will take precedence over the list in (30) due to the appearance of the features $[+\mathrm{sg}+\mathrm{pl}]$ which rule out all the VIs associated with one number feature, i.e. [+sg] or $[+\mathrm{pl}]$.

In (31a), the VI /ða:ni/ is a perfect nominee because it matches the greatest number of the features on the node, namely $[+\mathrm{pl}+\mathrm{sg}+$ masc $+\mathrm{sup}]$. This yields the correct form /ha:-ða:ni/.When the same demonstrative appears in a non-subject position, i.e. in the context of [-sup +/-obl] as in (31b), only the default VI /ðayni/wins outdue to the exclusion of the VI /ða:ni/from the competition for its feature [+sup]. The resulting output in (31b) will be /ha:-ðayni/.

The same results are obtained for the feminine dual nominative/accusative demonstratives. Consider their derivations below. 
32. a. ta:ni-k

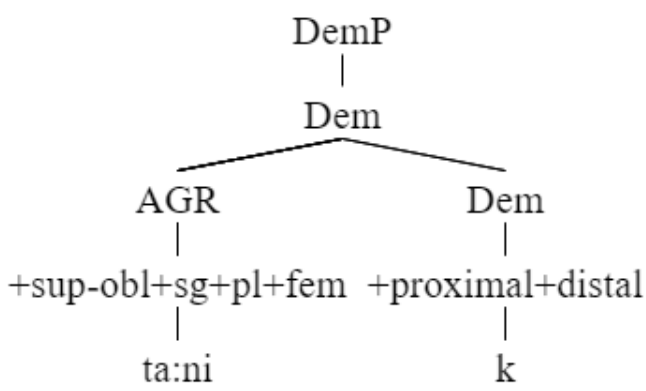

b. tayni-k

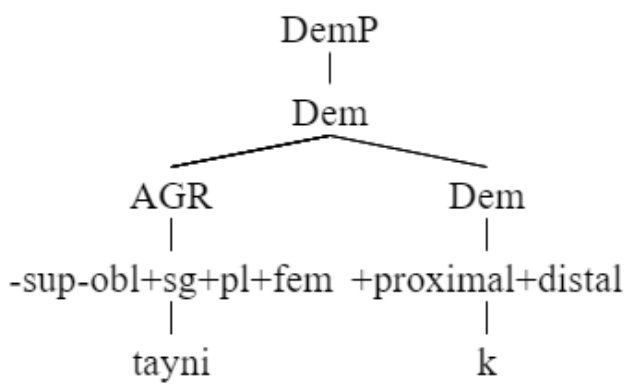

The structure in (32a) is nominative by virtue of the features [+sup -obl] whereas the one in (32b) is accusative considering the presence of [-sup -obl]. During the VI insertion, no VIs can expone the AGR node as perfectly as the VIs /ta:ni/ and /tayni/ respectively, thus yielding /ta:nik/ in (32a) and /taynik/ in (32b).

The remaining issue in dual demonstratives that is worth discussing relatestothe absence of CA distal dual demonstratives in Paradigm (1), namely the masculine forms /*ða:ni-lik; *ðayni-lik/or the feminine counterparts /*ta:ni-lik; *tayni-lik/. To refer to distant objects, the speakersof CA make use of the medial demonstratives /ða:ni-k, ðayni-k/ for masculine or /ta:ni-k, tayni-k/ for feminine. Thus, we are dealing with a morphological neutralization where medial demonstratives compensate for the absence of distal ones.

To capture such neutralization, one mightinvoke an impoverishment rule to delete the distal feature [+distal]in the context of the dual features $[+\mathrm{sg}+\mathrm{pl}]$ as in (33).

33. $[+$ distal $] \rightarrow \varnothing / \_[+\mathrm{sg}+\mathrm{pl}]$ 
Nonetheless, this proposal does not yield favorable results because the deletion of [+distal] also bleeds the insertion of the medial VI $/ \mathrm{k} /$ associated with [+proximal +distal]. The VI / $/$ / cannot win any longer given that [+distal] is removed from the structure.

Another possible proposal is to contextualize all the dual VI in (30) as shown in (34).

34. VI list for Dual Demonstratives

$$
\begin{aligned}
& \text { /ða:ni/ } \longleftrightarrow \text { [+pl +sg +masc +sup }] \quad\{+ \text { proximal (+distal) } \\
& \text { /ta:ni } \quad \longleftrightarrow \quad[+ \text { pl }+ \text { sg }+ \text { fem }+ \text { sup }] \quad\{+ \text { proximal (+distal) }\} \\
& / \text { ðayni } / \leftarrow \rightarrow \quad[+ \text { pl }+ \text { sg }+ \text { mas }] \quad\{+ \text { proximal }(+ \text { distal })\} \\
& \text { /tayni } / \longleftrightarrow \quad[+\mathrm{pl}+\mathrm{sg}+\mathrm{fem}] \quad\{+ \text { proximal }(+ \text { distal })\}
\end{aligned}
$$

This hypothesis is problematic as well. If the syntactic numeration begins with [-proximal +distal] which constitute the context of distal demonstratives, no VIs in (34) will be a candidate due to their over specified contextual features, particularly \{+proximal\}.Thus, the node of these phi-features will be empty for the absence of the candidate and only the deictic morpheme /lik/ inserts into Dem, generating an ill-formed instance. Under the worst circumstances, the morpheme /lik/ will appear in combination with a singular or plural demonstrative VI that discharges a subset of the features under AGR; yet, the combination will express the wrong interpretation of dual demonstratives. In CA, the singular or plural demonstratives such as /ða-lik/or/Pula:-lik/ do not bear the semantics of the distal dual demonstratives in Arabic.

The only possible solution to this problem is to resort tothe version of the impoverishment rule that switches feature values. These rules are known in the DM framework as Rules of Referral (Zwicky 1985; Stump 1993; Noyer 1998). Although Noyer (1998) adopts the same mechanism but restricts the value switch from the marked case to the unmarked one, i.e. from [+feature] to [-feature], the current study requires the reverse as theorized in Rules of Referral (Zwicky 1985; Stump 1993). Thus, in the environment of $[+\mathrm{sg}+\mathrm{pl}+$ distal $]$, I propose that the feature [-proximal] switches to [+proximal] as in (35).

$$
\text { 35. [-proximal] } \rightarrow[+ \text { proximal }] / \ldots[+\mathrm{sg}+\mathrm{pl}+\mathrm{distal}]
$$

Consider the derivation of distal dual masculine demonstratives below. 
36. a. ða:ni-?? (before Rule of Referral35)

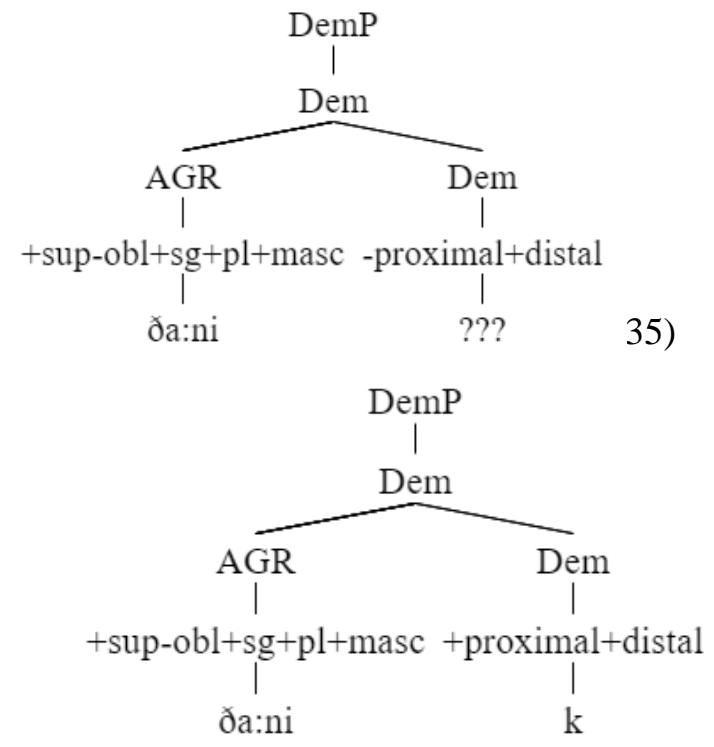

When the structure contains $[+\mathrm{sg}+\mathrm{pl}+$ distal] as in (36a), the feature [proximal] automatically shifts to [+proximal] as in (36b) under the application of rule (35). Such a value switch will immediately rule outthe VI /lik/ (associated with [+distal]) from competition; thus, the medial VI /-k/ will be the winner given its correspondence to more features in the structure [+proximal +distal]. One advantage of rule (35) follows from the fact that it applies at PF and keeps the semantics of distal information intact, irrespective of the morphological shape. The features [-proximal +distal] will be spelled out to both PF and LF. Thus, rule (35) will apply only at the level of PF yielding a different morphological shape, i.e. $/ \mathrm{k} /$ rather than $/ \mathrm{lik} /$. As for the distal interpretation of the derived demonstratives, it will be preserved at LF given that the interfaces PF and LF are impenetrable to each other in the syntactic theory (Chomsky 1995).

Let us now move to the derivation of the plural demonstrative whose two VIs as in the list (37).

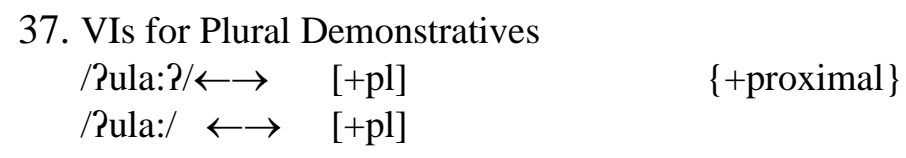

In (37), the VI /Pula:?/is specified with the contextual feature $\{+$ proximal $\}$. That is, the VI/Pula:?/is a candidate if and only if the numeration includes such a feature, i.e. if the demonstrative at hand is proximal having the features [+proximal -distal] or medial having [+proximal +distal]. On the other hand, if the 
computation operates on [-proximal], the VI/Pula:?/ is outlawed and the elsewhere case /Pula:/ inserts by default. This organization of (contextual) features neatly captures the missing form/*2ula?lik/from Paradigm (1). Consider the following derivations of the medial and distal plural demonstratives respectively.

38. a. Pula:?-k/Pula:-k

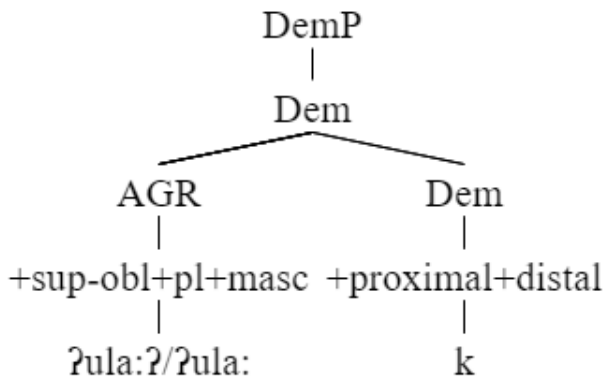

b. Pula:-lik

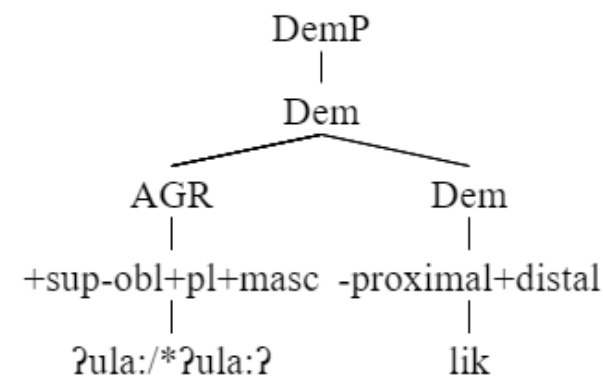

In $(38 \mathrm{a}, \mathrm{b})$, the AGR node has $[+\mathrm{pl}]$ feature. Whether the numeration introduces [+masc] or [+fem], or [+/-sup +/-obl] along with it, it does not matter as the resulting form will be always the same; the VIs in (37) are invariably underspecified for gender and case. In (38a), both the VIs /Pula:?/ or /Pula:/are equally competitive entries because they both match the same subset of the features on the node. Since the contextual specification of the VI /Pula:?/ (i.e. $\{+$ proximal\}) is met,itis the most commonly used form in CA. However, if /Pula:?/is not chosen, the default item /Pula:/ will insert as another option, capturing possible variations. By contrast, in $(38 \mathrm{~b})$, the structure involves [proximal +distal] and these features immediately abolish the legitimacy of the VI /Pula:P/, contextually related to $\{+$ proximal $\}$. This explains why the form /*?ula:?$\mathrm{lik} /$ is illicit in CA. Thus, as shown in (38b), the only winner is the default VI /Pula:/, giving rise to the wanted form /Pula:-lik/.

In light of the discussion above, the patterns of the CA demonstratives are elegantly handled within the framework of DM. That is, DM proves effective in generating all the correct instances and undergenerating the ill-formed ones. 


\subsection{An Alternative proposal}

In this section, I will address the issue whether the definiteness feature [+def] is copied from the DP to AGR alongside other phi features. Before tackling this issue, it is important to identify the two (in) definiteness markers in CA. In CA, nouns can be marked with either the definite article/prefix /Ral-/as in /2al-kita:b/ 'the book'or with the indefinite suffix /-n/ as in /kita:b-u-n/ 'a book'. These markers can be listed as VIs in (39).

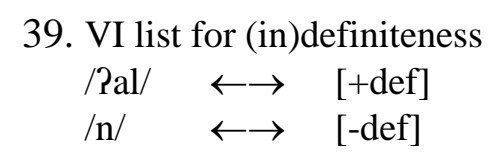

I assume that the (in)definiteness features [+/-def] appear under the head D. Thus, one might stipulate that these features should be copied in demonstrative phrases from D to the AGR node in the same fashion the case, number and gender features are copied from Num and Gen. Given that demonstratives only occur in the contexts of definite noun phrases, the exclusion of [+def] from the copying operation discussed in section (4.2) seems non-systematic and raises questions regarding the feature distribution.

Under this hypothesis, however, I argue that copying the feature [+def] does not cause problems for the majority of the VIs. Consider the derivation of the proximal masculine singular demonstrative in (40).

40. ha:-ða

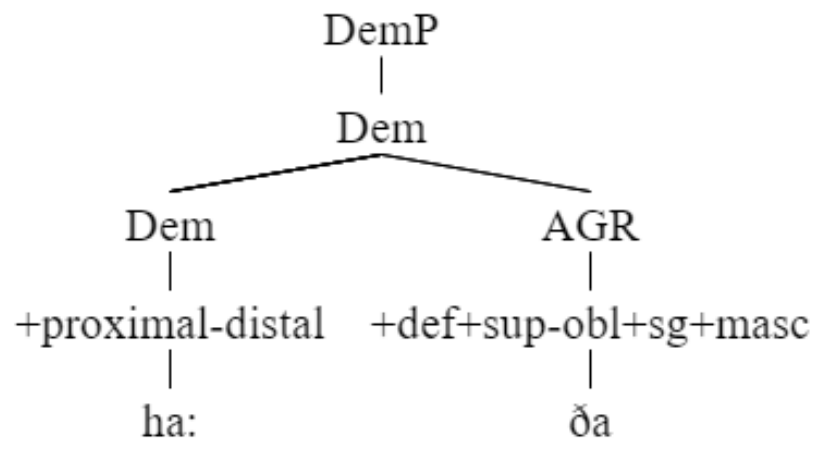

Let us assume as represented in (40) that AGR node copies [+def] from the DP along the other features. Like case features which are not spelled out in most cases, we can simply argue that the feature [+def] behaves similarly. The definite feature [+def] appears in a bundle under one node; thus, the bundle on AGR in (40) will be discharged at once as /ða/ which matches the maximal subset ([+sg +masc]). The definite article / $\mathrm{Ral} /($ corresponding to only one feature [+def]) is not a possible candidate at all. Nearly all the demonstrative VIs in (22) are associated 
with two features and more, hence taking priority over the definite article that is specified with only one feature.

Nonetheless, the plural demonstratives/?ula:?/ or/?ula:/are the only VIs that have one feature, i.e. [+pl],rendering iton a competitive par with the definite article / $\mathrm{Pal} /($ specified with [+def]) as shown in the list (41).

41. VIs for Plural Demonstratives and Definiteness

$$
\begin{array}{llll}
\text { Pula:? } & \leftarrow & {[+\mathrm{pl}]} & \{+ \text { proximal }\} \\
\text { Pula: } & \leftarrow \rightarrow & {[+\mathrm{pl}]} & \\
\text { Pal } & \leftarrow \rightarrow & {[+\mathrm{def}]} &
\end{array}
$$

Consider the derivation of the plural masculine demonstrative below.

42. Pula:-lik

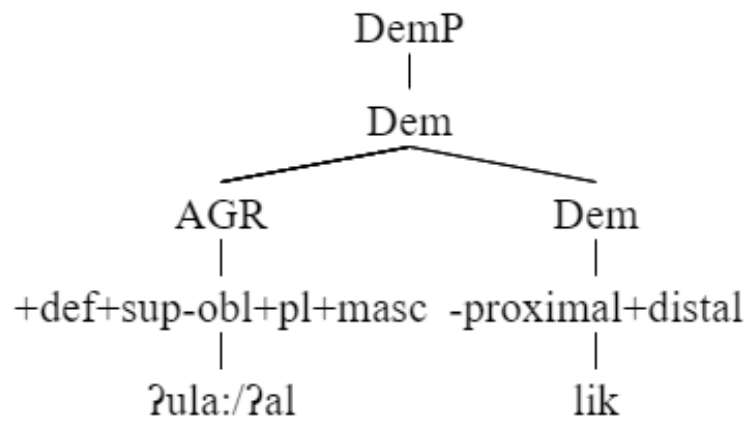

In (42), AGR bears [+def] and [+pl] simultaneously. The VI /Pula:?/ is excluded for being specific to the context of $\{+$ proximal $\}$, an absent feature in the structure (42). However, both the VIs /Pula:/ and /Pal/ are equal candidates and each of them is correlated with one feature in the node. Under this circumstance, we expect two results: /Pula:-lik/ or /*?al-lik/; yet, the latter does not exist in Arabic.

This problem can be overcome by an impoverishment rule which targets $[+\mathrm{def}]$ and removes it in the context of [+pl] as laid out in (43).

$$
\text { 43. [+def] } \rightarrow \varnothing /
$$

In the context of $[+\mathrm{pl}]$, the $[+\mathrm{def}]$ will be deleted as shown in (44). Thus, the only remaining entry to spell out the features on the AGR will be/?ula:/. 
44. Pula:-lik

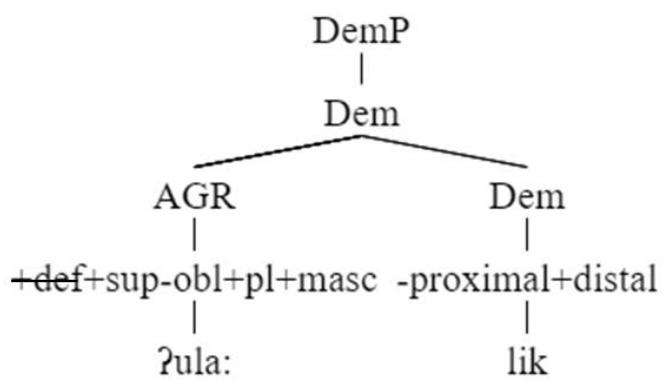

In conclusion, whether [+def] is copied onto AGR or not, the derivations of all the CA demonstratives still follow neatly with the implementation of rule (43) only in the contexts of plural demonstratives.

\section{Conclusion}

The current study examines the demonstrative patterns in CA. It has been noticed that the CA demonstratives consist of pieces representing different grammatical functions:(i) the deictic morphemes (proximal, medial and distal) and (ii) the morphemes correlating with number, gender and case. I propose that deictic information occupies the head Dem, whereas the other phi features are copied from the modified DP to AGR node via Feature Copying at PF. This proposal captures the fact that Arabic demonstratives, on par with other nominal modifiers, agree with nouns. Thus, I postulate that demonstratives head their own projection (DemP) and project above DP.

Associating every morpheme with its corresponding features, I show that the CA demonstrative system fares well under the DM framework. All the proposed VI lists generate the desirable forms and exclude the unwanted ones. Under certain conditions, however, I further specify the VIs with context-sensitive features. These contextual specifications regulate the competition of the VIs in a principled manner.

For a few advanced cases, two impoverishment rules have been stipulated. Under the assumption that the definiteness feature [+def] is copied with other phi features, an impoverishment rule is formulated to reconcile the competition between the definite article / $\mathrm{Ral} /$ and the plural demonstrative /Pula:/. I proposed that the definiteness feature [+def] is deleted in the environment of [+pl], allowing the plural demonstrative / Pula:/ to win. To account for the gaps in the paradigm for the distal dual demonstratives, I propose another impoverishment rule with a value-switching capability. This rule was posited as a last resort after two alternative proposals failed. Although Noyer (1998) proposes that value-switching rules should operate from the marked to unmarked cases, our rule takes a reverse direction, i.e. it switches a feature from the less marked [-proximal] to the marked one [+proximal] in accordance with Rules of Referral (Zwicky 1985, Stump1993). Without such a rule, the absence of the distal dual demonstratives and their substitution with the medial dual demonstratives will remain an unanswered question. Given that the referral rules have been neglected in DM, 
this study provides support to them for handling neutralization in paradigm-based morphology.

\section{Endnotes}

${ }^{1}$ Acknowledgement: The author extends his appreciation to the Deanship of Scientific Research at King Khalid University for funding this work through General Research Project under grant number (G. R. P- 251-40).

Abbreviations used in this article are as follows: 1=First Person; 2=Second Person; 3=Third Person; ACC=Accusative; $\mathrm{CA}=$ Classical Arabic; DEM=Demonstrative; DM=Distributed Morphology; DP=Determiner Phrase; DU=Dual; F=Feminine; GEN=Genitive; IMPERF=Imperfective; LF=Logical Form; M=Masculine; MP=Minimalist Program; MS=Morphological Structure; MSA=Modern Standard Arabic; $\quad$ NOM=Nominative; $\quad$ PASS=Passive; PERF=Perfective; PF=Phonetic Form; PL=Plural; $\mathrm{S}=$ Singular; UG=Universal Grammar; VI=Vocabulary Item

${ }^{2}$ One reviewer proposes readjustment rules for the derivation of the phonological alternations of both forms of the plural demonstrative (/Pula:?/ and /Pula:/) or the variants of the feminine singular demonstrative (/ðih/-/ði/ and /tih/-/ti/). In this paper, I do not appeal to these phonological rules because they are theoretically problematic and have been banished from the DM framework. For instance, Siddiqi (2009) proposes that roots such as $V_{\text {run }}$ and $V_{\text {ran compete as separate VIs }}$ rather than assuming that the basic root $\bigvee_{\text {run }}$ undergoes a readjustment rule that shifts the vowel $/ \mathrm{u} /$ into $/ \mathrm{a} /$ in the past tense contexts.

${ }^{3}$ It should be noted that this is a simplified DP derivation in Arabic. The situation is much more complex. In the tree (15) and (17), I assume that the root $V_{\mathrm{j} 1}$ is attached to the category-defining head $n$ (making up $/ \operatorname{mad} 3 a 1 /$ ). After the combination /madzal-at-a:ni/ reaches the head D, the definite article / Ral/ will be abnormally attached as a suffix yielding the illicit form /*madzal-at-a:ni-?al/. To obtain the right affix order, we may need to stipulate a local dislocation rule which is a common postsyntactic operation in DM. For morphophonological wellformedness conditions, this operation shifts the definite article / $\mathrm{Pal} /$ as a prefix to yield the well-formed word /Pal-madzal-at-a:ni/ 'the two magazines'. These requirements will be clear if we have already provided the VI lists for gender/definiteness/case/number for Arabic noun phrases but this is beyond the scope of the paper, which restricts the attention to the complex demonstrative paradigm (for a full DM-based analysis of Arabic DP, see Alqarni 2015). University of Queensland 
Muteb A. Alqarni

P.O. Box 250

96889

King Khalid University

College of Science and Arts, Tanuma

Email: moteebalqarni@kku.edu.sa

mutebalqarni@gmail.com

\section{References}

Acquaviva, Paolo. (2008). 'Roots and lexicality in distributed morphology'.Retrieved at https://ling.auf.net/lingbuzz/000654(on the $20^{\text {th }}$ ofMarch, 2019).

Ahmed, Amer. (2015). 'On agreement affixes, incorporated pronouns, and cliticsin Standard Arabic'. SKY Journal of Linguistics, 28 (1): 67-102.

AlBarrag, Thamir. (2014). Noun phrases in Urban Hijazi Arabic: A distributed morphology approach. Unpublished $\mathrm{PhD}$ Dissertation, University of Queensland, Australia.

Albuhayri, Salem. (2013). Thepronominal system in Standard Arabic: Strong, cliticand affixal pronouns.MA Thesis, Arizona State University, USA.

Alghamdi, Abdullah. (2015). Fromroot to nunation: The morphology of Arabic nouns. Published PhD Dissertation, University of New South Wales, UK.

AlQahtani, Saleh. (2016). Thestructure and distribution of determiner phrases in Arabic: Standard Arabic and Saudi Dialects. Unpublished PhD Dissertation, University of Ottawa.

Alqarni, Muteb. (2015). Themorphosyntax of numeral-noun constructions in Modern Standard Arabic. Published PhD Dissertation, University of Florida.

Alqarni, Muteb. (2018). 'Pronominalsystem in Standard Arabic: A distributed morphology analysis'. Albha University Journal for Human Sciences. Retrieved at https://ling.auf.net/lingbuzz/004374(on the $15^{\text {th }}$ of December, 2018).

Alqassas, Ahmad. (2013). 'Thedefinite marker in Arabic: Morphological realization of the syntactic head D or a [DEF] feature'. Berkeley Linguistics Society, 1-15.

Baker, Mark. (1985). 'The mirror principle and morphosyntactic explanation'. Linguistic Inquiry, 3 (16): 373-415.

Bobaljik, Jonathan. (2008). 'Where's Phi? Agreement as a post-syntactic operation'. In Daniel Harbour, David Adger, and Susana Béjar(eds.)PhiTheory: Phi features across Interfaces and Modules 295-328.Oxford University Press.

Chomsky, Noam.(1995). The Minimalist Program. Cambridge: MIT Press. 
Chomsky, Noam. (2000). 'Minimalist inquiries: The framework'. In Roger Martin, David Michaels, Juan Uriagereka and Samuel Jay Keyser (eds.), In Step by Step: Essays in Minimalist Syntax in Honor of Howard Lasnik, 89155. Cambridge, Mass: MIT Press.

Chomsky, Noam. (2001). 'Derivation by phase'. In Michael Kenstowicz (ed.), Ken Hale: A Life in Language, 1-52. Cambridge, Mass.: MIT Press.

Chomsky, Noam.(2004). 'Beyond explanatory adequacy'.In Adriana Belletti, Structures and Beyond: The Cartography of Syntactic Structures, 3: 104-131. Oxford: Oxford University Press.

Cinque, Guglielmo. (1999). Adverbs and Functional Heads: a Cross-linguistic Perspective. Oxford University Press.

Cowell, Mark W.(1964).A Reference Grammar of Syrian Arabic. Washington D.C.: Georgetown University Press.

Dalrymple, Mary. (2001). Syntax and Semantics: Lexical Functional Grammar. New York, NY: Academic Press.

De Belder, Marijke. (2011). Roots and Affixes: Eliminating Lexical Categories from Syntax. Brussels: HU Brussel, Utrecht University.

Diessel, Holger.(1999). Demonstratives: Form, Function, and Gammaticalization. Amesterdam: John Benjamins.

Dixon, R. M. W. (2003). 'Demonstratives: A cross-linguistic typology'. Studies in Language, 27 (1): 61-112.

Embick, Davidand Alec Marantz. (2008). 'Architecture and blocking'.Linguistic Inquiry, 39(1): 1-53.

Embick, David and Rolf Noyer.(2005). 'Distributed morphology and the syntax/morphology interface'.InGillian Ramchand and Charles Reiss (ed.), The Oxford Handbook of Linguistic Interfaces 1-28. Oxford: Oxford University Press.

Embick, David. (1997). Voice and the interfaces of syntax.PhD dissertation, University of Pennsylvania.

Embick, David. (1998). 'Voice systems and the syntax/morphology interface'. In Heidi Harley, (ed.), Papers from the UPenn/MIT Roundtable on Argument Structure and Aspect, 32: 41-72.MITWPL.

Enfield, N. J.(2003). 'Demonstratives in space and interaction: Data from Lao speakers and implications for semantic analysis'. Language, 79 (1): 82-117.

Ernst, Thomas. (2002). The Syntax of Adjuncts. Cambridge University Press.

Fassi-Fehri, Abdelkader.(1999). 'Arabic modifying adjectives and DP structures'.StudiaLinguistica, 53: 105-154.

Fischer, Wolfdietrich.(2002). A Grammar of Classical Arabic.Yale University Press.

Greenbaum, Sidney and Randolph Quirk.(1990). A Student's Grammar of the English Language. London: Longman.

Halle, Morris and Alec Marantz.(1993). 'Distributed morphology and the pieces of inflection'.In Samuel Keyser and Ken Hale, TheViewFromBuilding, 20: 111-76. Cambridge, MA: MIT Press. 
Halle, MorrisandAlec Marantz.(1994). 'Some key features of distributed morphology'.In Andrew Carnie, Heidi Harley and T. Bures (ed.), MIT Working Papers In Linguistics 21: Papers on Phonology and Morphology, 275-88. Cambridge: MIT Working Papers in Linguistics.

Halle, Morris. (1997). 'Distributed morphology: Impoverishment and fission'. MIT Working Papers in Linguistics, 30: 425-449.

Harley, Heidi and Rolf Noyer. (1999). 'State-of-the-article: Distributed morphology'. Glot International, 4 (4): 3-9.

Harley, Heid and RolfNoyer. (2000). 'Formal versus encyclopedic properties of vocabulary: Evidence from nominalisations'. In Bert Peeters (ed.), The Lexicon-Encyclopedia Interface, 349-74. Amsterdam: Elsevier Press.

Harley, Heidi andElizabeth Ritter. (2002). 'Person and number in pronouns: Afeature-geometric analysis'. Language, 78 (3): 482-526.

Harley, Heidi. (2010). 'Affixation and the mirror principle'. In RaffaellaFolli and Christiane Ullbricht (ed.), Interfaces in Linguistics, 166-186. Oxford: Oxford University Press.

Harley, Heidi. (2014). 'On the identity of roots'.Theoretical Linguistics, 40 (3): 225-276.

Hassan, Abbas. (1987). Al-naћwAl-wa:fii (The Complete Grammar).4 vols. 3rd Edition. Cairo: DaarAl-ma'arif.

Marantz, Alec. (1997a). 'No escape from syntax: Don't try morphological analysis in the privacy of your own lexicon'. UPenn Working Papers in Linguistics, 4: 201-225.

Marantz, Alec. (1997b). 'Cat as a phrasal idiom: Stem suppletion, or the arbitrariness of the sign'. Paper presented at the Université de Paris VIII.

Marantz, Alec. (1991). 'Case and licensing'. In German Westphal, Benjamin AoandHee-RahkChae (ed.), Proceedings of the 8th Eastern States Conference on Linguistics. Ithaca, NY: Cornel Linguistics Club, 234-253.

McFadden, Thomas. (2004).Thelocation of case in the derivation: A study on the syntax/morphology interface. Published $\mathrm{PhD}$ dissertation, University of Pennsylvania.

Mohammad, Mohammad.(1988). 'On the parallelism between IP and DP'.Proceedings of the West Coast Conference on Formal Linguistics, 7: 241-254.

Noyer, Rolf.(1998). 'Impoverishment theory and morphosyntactic markedness'. In Steven G. Lapointe and Diane K. Brentari (ed.), Morphology and ItsRelation to Phonology and Syntax, 264-285. Palo Alto: CSLI.

Picallo, Carme.(1991). 'Nominals and nominalizations in Catalan'.Probus, 3: 279-316.

Ritter, Elizabeth.(1991). 'Evidence for number as a nominal head'.Paper presented at the GLOW Conference, Leiden.

Ryding, Karin.(2005). A Reference Grammar of Modern Standard Arabic. Cambridge University Press.

Sawaie, Mohammed.(2014). Fundamentals of Arabic Grammar. Routledge. 
Shlonsky, Ur. (2004). 'The form of Semitic noun phrases'. Lingua, 114 (12): 1465-1526

Siddiqi, Daniel (2009). Syntax Within the Word: Economy, Allomorphy, and Argument Selection in Distributed Morphology. John Benjamin Publishing.

Thackston, Wheeler. (2000). An Introduction to Koranic and Classical Arabic: An Elementary Grammar of the Language. Maryland: IBEX Publishers Bethesda.

Zwicky,Arnold. (1985). 'How to describe inflection'. Proceedings of the Berkeley Linguistics Society, 11:372-386. 